\title{
EDFA AND EYCDFA POWER BOOSTER FOR SECURED, HIGH SPEED AND MULTIPLE WAVELENGTH SERVICES IN OPTICAL COMMUNICATION SYSTEMS USING WDM AND QUAD-SINGLE FORWARD AND TRI BACKWARD PUMPING TECHNIQUE
}

\author{
S. Semmalar \\ Research Scholar, \\ SCSVMV University \\ Kanchipuram, India
}

\author{
S. Malarkkan \\ Principal, \\ Manakula Vinayagar Institute of technology \\ Pondicherry, India.
}

\begin{abstract}
Proposed the EDFA and EYCDFA power booster (Erbium Doped Fiber Amplifier- Erbium ytterbium co doped fiber amplifier) with quad pumping for high speed and multi wavelength services in an optical communication. The proposed EDFA and EYCDFA power booster with WDM(Wavelength division multiplexing) simulated by dual forward and Backward pumping, Dual-backward pumping, Tri-single forward and dual backward pumping and Quadsingle forward and tri-backward pumping with respect to Pump power and fiber Length. The parameters Input Optical power, Output Optical power, Forward Signal power, Backward Signal power measured and determined the speed of transmission in all types of pumping methods. From that the proposed EDFA- ans EYCDFA power booster with WDM quad pumping is the best suitable for secured high speed optical telecommunication systems. The results shown in Quad pumping Output optical power is maximum 25.2dB and optimum spectral forward Signal power is $30.5 \mathrm{dBm}$ and very

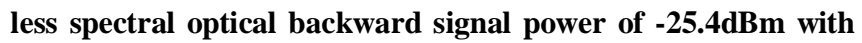
Length 5m.
\end{abstract}

Keywords - EDFA, EYCDFA, WDM, Pumping, optical Power, Fiber Length, Pump power and Quad pumping.

\section{INTRODUCTION}

Nowadays the demand of largest amount of data communication needs to require the secured high speed and strengthen fiber optic communication systems used as the power boosters, master oscillator power amplifiers and WIFI fiber optic adapter carry the wide bandwidth optical signals in terms of $\mathrm{Tb} / \mathrm{s}$ in communication systems used in internet communication, telecommunication networks, Dispersions managed links, DWDM network based onoptical packet switching, high speed WDM systems and Multi vendor networks. Multi vendor netowrk is the computer network supports tools from one more vendor or provider. The centralized computer network for business providing and high power operations and developing the idea environment that lets users attend to everyday challenges. Outer layer of the network performing centralized data centers enables to work network more intelligently. Data traffic kept very closer to customers gives services are faster, lager capacity with more efficient and also key management control and high secured functions operated centrally.

High speed optical communication with WDM avoids the cross talk using guard band $75 \mathrm{GHZ}$ between the user wavelengths, also provides secured communication with minimum interferences. Speed of the optical transmission can be given below

Speed $=$ Distance $/$ Time $\mathrm{m} / \mathrm{s}$

Where

Speed of the Inline-EYCDFA EDFA communication in $\mathrm{m} / \mathrm{s}$. Distance is the Length of the fiber in meters

Time is the execution time of the simulation models in seconds

Speed of optical transmission calculated in all pumping methods. Speed in $\mathrm{m} / \mathrm{s}$ can be calculated using distance (Length of the fiber in metres) and time (Execution time of simulation model) in seconds using the Eq.1 and plotted the values with the comparison of all pumping methods. Speed of transmission increased in quad pumping technique compared to all pumping methods. 


\section{International Journal of Engineering Applied Sciences and Technology, 2021 \\ Vol. 5, Issue 12, ISSN No. 2455-2143, Pages 195-201 \\ Published Online April 2021 in IJEAST (http://www.ijeast.com)}

High power fiber optic communication needs fiber optic amplifiers like EDFA, EYCDFA are the very important amplifiers to boost the optical power without the need of regenerators. The optical amplifier EDFA and EYCDFA uses various pumping techniques Single forward and single backward pumping, dual backward pumping, single forward and dual backward pumping, single forward and tribackward pumping. Moreover EDFA uses the wavelength range of $1500 \mathrm{~nm}$ to $1600 \mathrm{~nm}$ and EYCDFA uses $1100 \mathrm{~nm}$ to $1600 \mathrm{~nm}$ wavelength ranges, both the optical amplifiers are used in multi wavelength services in optical communication systems. The Pumping methods used to excite the atoms present in the ground state energy level transverse to higher energy level called as Absorption. The atoms present in the higher energy level come down to lower energy level called as emission. The pumping using multiple wavelengths $980 \mathrm{~nm}$ and $1480 \mathrm{~nm}$ gives various intensity optical outputs.

\section{BACKGROUND}

The paper [1] discussed the optical amplifiers performance analyzed the output power and quality factor and gives EDFA gives highest output power by varying the transmission distance of 60 to $180 \mathrm{~km}$.[2] paper discussed the hybrid amplifiers performance EDFA, SOA and RAMAN connected as hybrid model with different channels to analyzed the eye opening and closing and BER. The paper [3] deals the EDFA based WDM ring networks to measured the OSNR and BER. The paper [4] discussed the EDFA- TDFA series configuration to increase the transmission capacity for the optical communication systems.

The [5] paper discussed the role of all the optical amplifiers like EDFA, SOA and RAMAN analyzed theoretically. [6] The paper compares all the types of amplifiers with its specific advantages and analyzed the output power and length. The paper [7] discussed the cascaded EDFA and EYCDFA gives the gain flattening without ant gain shaping elements used the model. The paper[8] discusses the EDFA with WDM systems to deals the ASE noise

\section{PROPOSED WORK}

The proposed work is the simulation model in which the EDFA and EYCDFA connected together with quad pumping techniques. The simulation model consists of four Optical transmitters are coupled to 4:1 WDM multiplexer. The multiplexer output connected to the pump coupler co propagating. It couples the multiplexer output and forward pumping of wavelength $980 \mathrm{~nm}$. The output of pump coupler connected the EYCDFA and EDFA connected together to get the maximum optical output power and high forward signal power and less backward signal power. So the EYCDFA and EDFA connected model acts as power booster in high speed and multiple wavelength services in optical communication systems. In WDM multiplexed output, output of pump coupler, EYCDFA output, EDFA output, optical power connected to measure the optical power. Dual port WDM analyzer connected between input and output of the device to measure the gain and noise figure with minimum and maximum wavelength ranges. Output Spectrum Analyzer connected to each input and output stage to measure forward and backward signal power and noise power. Forward signal power is necessary to get maximum output power to transmit the signal properly. Backward signal power is reflected power and is not necessary for the transmission.

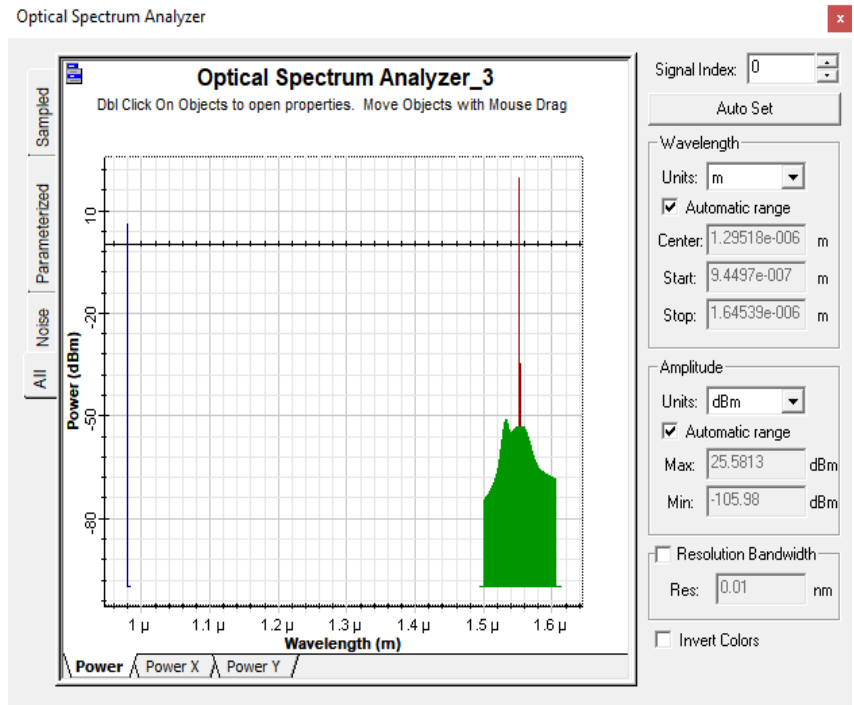

Fig. 3. OSA output EDFA1-PP=100mw, Length $=5 \mathrm{~m}$

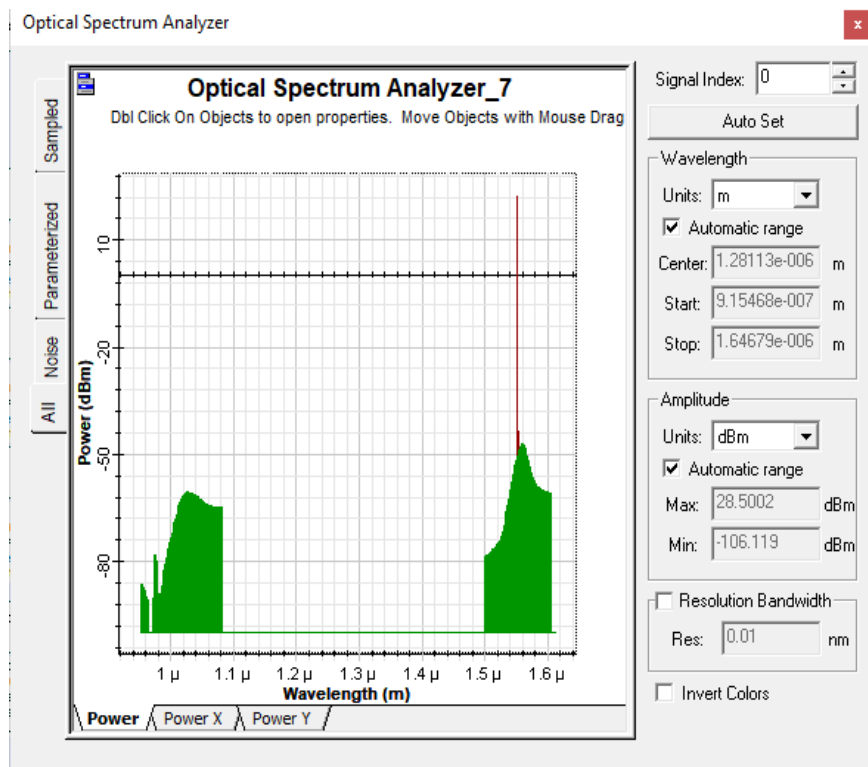

Fig. 4. OSA output of EDFA2- $\mathrm{PP}=100 \mathrm{mw}$ and Length $=5 \mathrm{~m}$ 


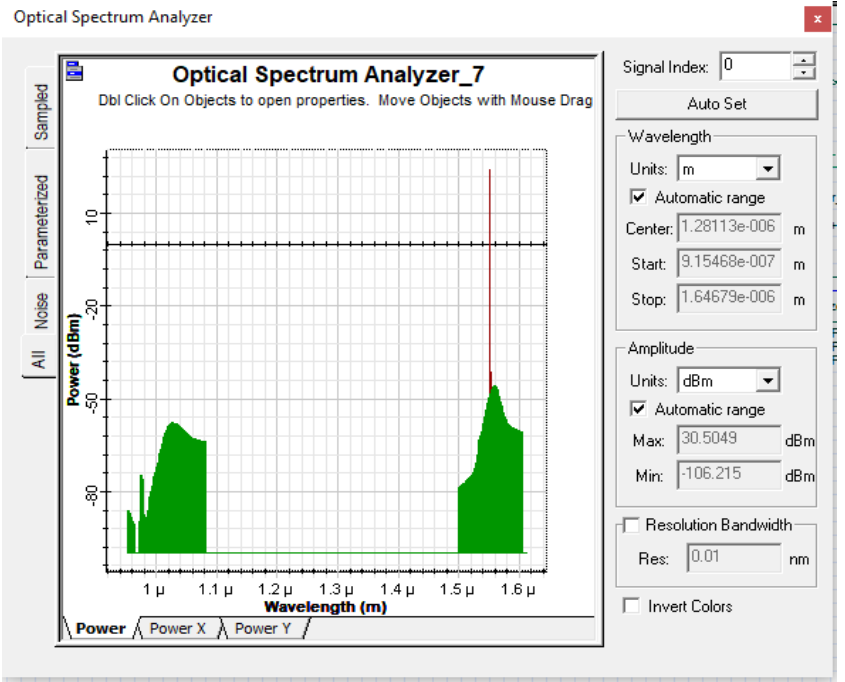

Fig. 5. OSA output of EDFA2 with $\mathrm{pp}=150 \mathrm{mw}$ and $\mathrm{l}=5 \mathrm{~m}$

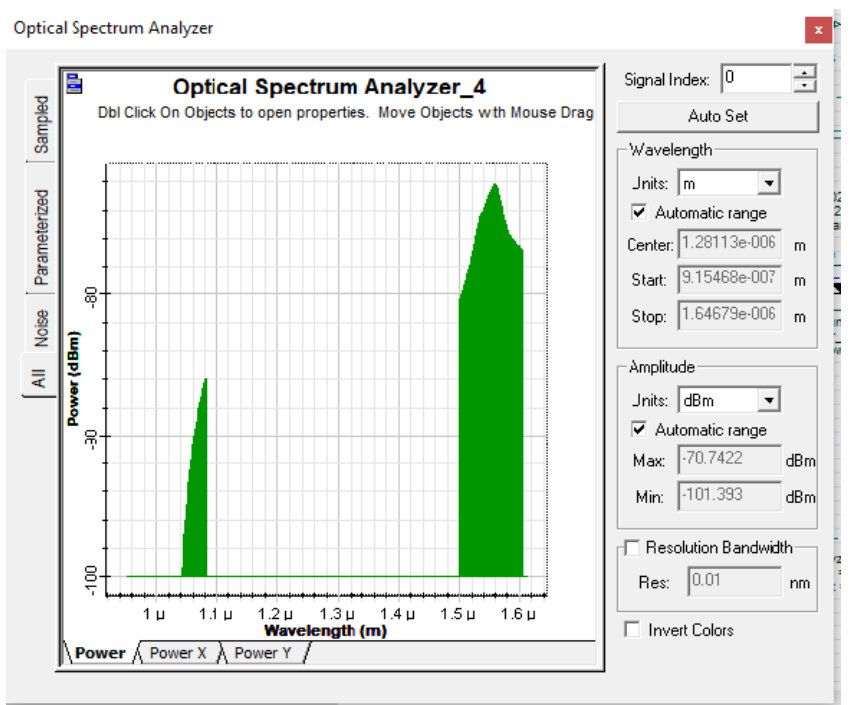

Fig. 6. OSA backward output of EYCDFA with $\mathrm{pp}=100 \mathrm{mw}$ and $\mathrm{L}=10 \mathrm{~m}$

\section{RESULTS AND DISCUSSION}

The EDFA and EYCDFA connected in quad pumping with wavelength $980 \mathrm{~nm}$, the output parameters output amplified optical power, forward and backward signal power are measured from output of each device in proposed simulation model.

The speed of transmission determined from the equation Eq.(1) by distance that is length of the fiber in metre and time is taken from the execution time of the simulation in seconds. The amplified output optical power measured from the optical meter connected in the output each fiber amplifier

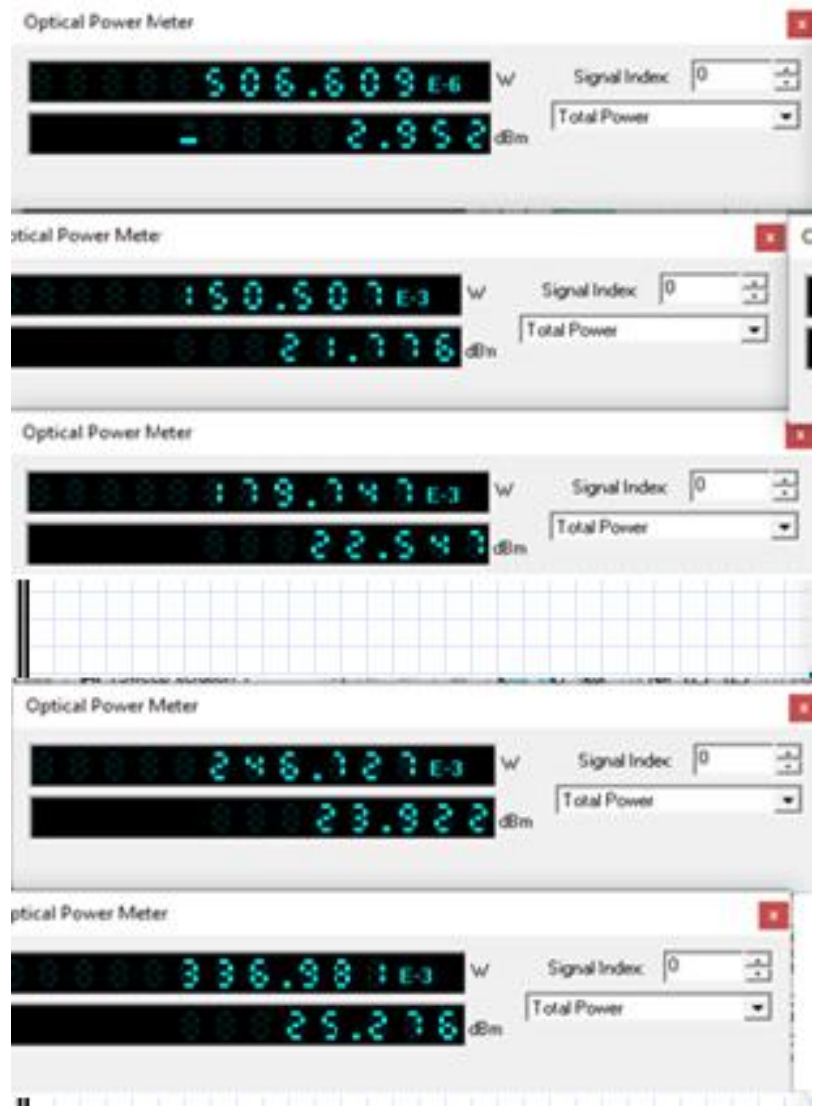

Fig. 7. .Quad pumping optical power meter outputs of Multiplexer, forward pumping output, EDFA1, EYCDFA and EDFA2 with fiber length-5m and pump power $21.7 \mathrm{dBm}$

Forward and backward signal power measured using the optical spectrum analyzer connected input and output ports of fiber amplifiers to measure the forward and backward signal powers. Fig.2. shows the OSA output of Multiplexed input (left side) and forward pumping output (right side) . Fig.3. shows the Optical spectrum analyzer (OSA) output, $25.5 \mathrm{dBm}$ denotes output forward signal power of EDFA1 with pump power $=100 \mathrm{mw}$ and $\mathrm{L}=5 \mathrm{~m}$, Fig. 4 . shows the OSA output $28.5 \mathrm{dBm}$ denotes output forward signal power of EDFA2 with pump power $=100 \mathrm{mw}$ and $\mathrm{L}=5 \mathrm{~m}$, Fig.5. shows the OSA output $30.5 \mathrm{dBm}$ denotes output forward signal power of EDFA2 with pump power $=150 \mathrm{mw}$ and $\mathrm{L}=5 \mathrm{~m}$,

Fig 6. Shows OSA output $-70.7 \mathrm{dBm}$ denotes output backward signal power of EYCDFA with pump power $=100 \mathrm{mw}$ and $\mathrm{L}=10 \mathrm{~m}$. Fig.7. shows the speed of transmission of all pumping methods. Speed of the optical communication inversely proportional to time and directly proportional to distance and decides how much data transmitted and received using fiber within a sec.

Fig 8.shows the output of optical meter connected in each stage of all devices used, optical meter output maximum value measured as $336.98 \mathrm{mw}$. 
International Journal of Engineering Applied Sciences and Technology, 2021

Vol. 5, Issue 12, ISSN No. 2455-2143, Pages 195-201

Published Online April 2021 in IJEAST (http://www.ijeast.com)

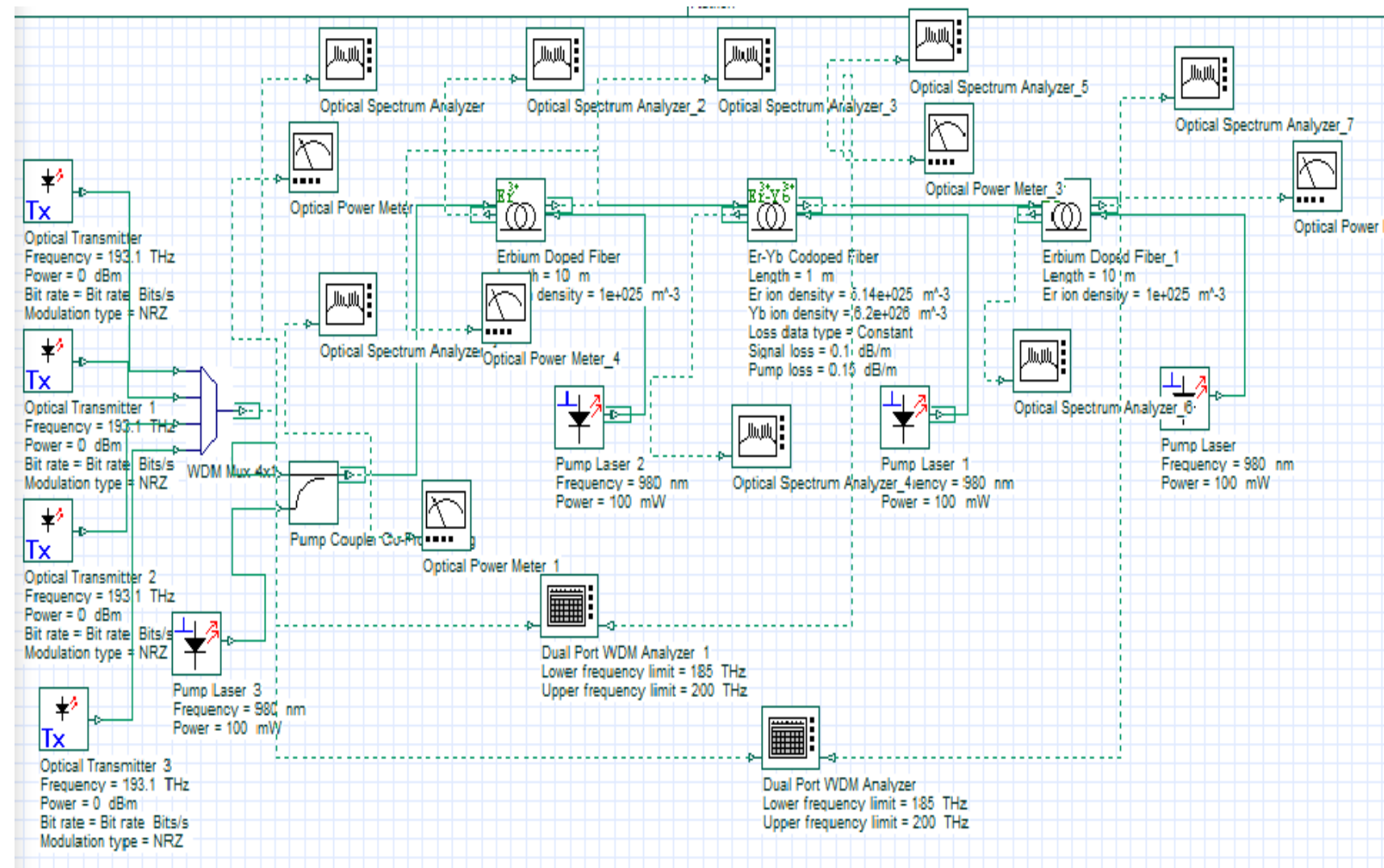

Fig 1: EDFA-EYCDFA power booster with single forward and tri backward pumping technique.
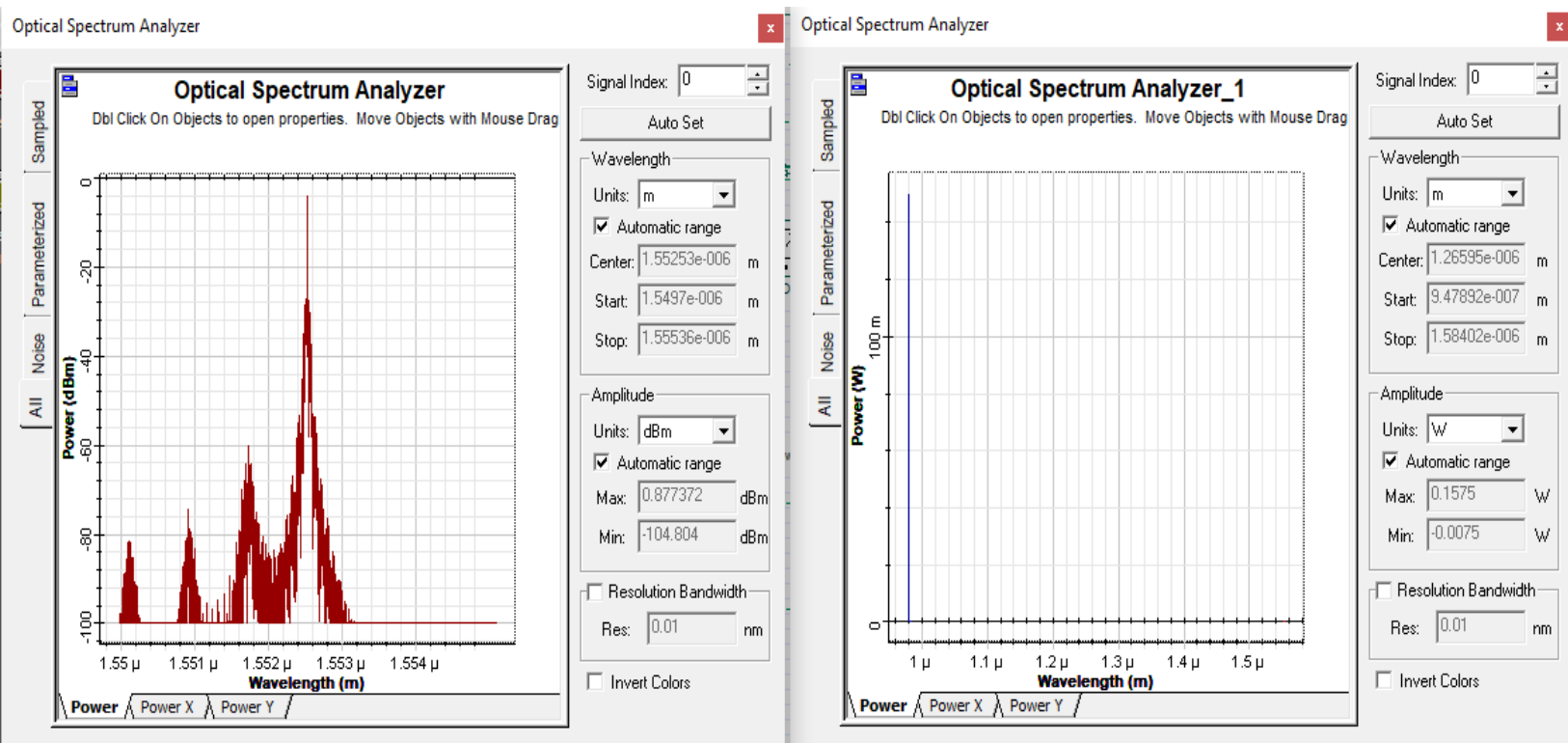

Fig.2. Optical Spectrum analyzer output of Multiplexed input and forward pumping output 
Published Online April 2021 in IJEAST (http://www.ijeast.com)

TABLE 1 - Optical power meter output and OSA output of EDFA and EYCDFA with Pump power $=20 \mathrm{~dB}$ and Length $=5 \mathrm{~m}$

\begin{tabular}{|l|c|c|c|c|c|c|}
\hline \multicolumn{5}{|c|}{$\begin{array}{l}\text { EDFA=5m, EYCDFA=1m, Multiplexed output= -2.9dB, Pump } \\
\text { power=20dB and Input power= 1mw(0dB) }\end{array}$} \\
\hline $\begin{array}{c}\text { Optical } \\
\text { amplifier } \\
\text { with type of } \\
\text { pumping } \\
\text { used }\end{array}$ & \multicolumn{2}{|c|}{$\begin{array}{c}\text { Optical Power } \\
\text { output of } \\
\text { EYCDFA and } \\
\text { EDFA (dBm) }\end{array}$} & $\begin{array}{c}\text { Spectral optical } \\
\text { Forward Signal } \\
\text { power of } \\
\text { EYCDFA and } \\
\text { EDFA (dBm) }\end{array}$ & $\begin{array}{c}\text { Spectral optical } \\
\text { Backward } \\
\text { Signal power of } \\
\text { EYCDFA and } \\
\text { EDFA (dBm) }\end{array}$ \\
\hline $\begin{array}{l}\text { Dual } \\
\text { Forward and } \\
\text { Backward } \\
\text { Pumping }\end{array}$ & 1 & 17 & 5 & 22.4 & -24 & 7.86 \\
\hline $\begin{array}{l}\text { Dual } \\
\text { backward } \\
\text { Pumping }\end{array}$ & 15.2 & 19.17 & 2.83 & 23 & -72.7 & 9.1 \\
\hline $\begin{array}{l}\text { Tri-single } \\
\text { forward and } \\
\text { dual } \\
\text { backward } \\
\text { pumping }\end{array}$ & 15.8 & 19.6 & 14.6 & 23.6 & -25.47 & 4.2 \\
\hline $\begin{array}{l}\text { Quad- single } \\
\text { forward and } \\
\text { tri-backward } \\
\text { pumping }\end{array}$ & $\mathbf{2 1 . 9}$ & $\mathbf{2 3 . 3}$ & $\mathbf{2 7 . 0 5}$ & $\mathbf{2 8 . 5}$ & $\mathbf{- 7 0 . 5}$ & $\mathbf{0 . 5 9}$ \\
\hline
\end{tabular}

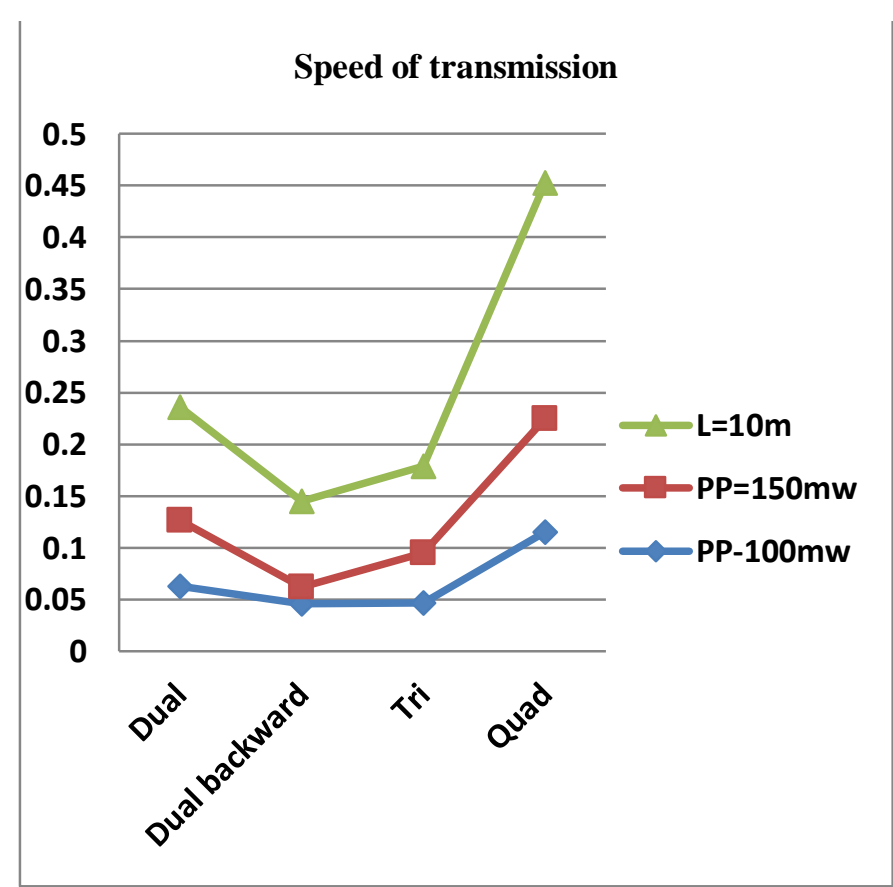

Fig. 7. Line chart of speed of transmission with respect to pump power and fiber length
TABLE 2. :Optical power meter output and OSA output of EDFA and EYCDFA with Pump power $=21.7 \mathrm{~dB}$ and Length $=5 \mathrm{~m}$

\begin{tabular}{|l|l|l|l|l|l|l|}
\hline \multicolumn{5}{|c|}{$\begin{array}{c}\text { EDFA=5m, EYCDFA=1m, Multiplexed output= -2.9dB, Pump } \\
\text { power=21.7dB and Input power= 1mw(0dB) }\end{array}$} \\
\hline $\begin{array}{c}\text { Optical } \\
\text { amplifier } \\
\text { with type of } \\
\text { pumping } \\
\text { used }\end{array}$ & $\begin{array}{c}\text { Optical } \\
\text { Power } \\
\text { output of } \\
\text { EYCDFA } \\
\text { and EDFA } \\
\text { (dBm) }\end{array}$ & $\begin{array}{c}\text { Spectral optical } \\
\text { Forward Signal } \\
\text { power of } \\
\text { EYCDFA and } \\
\text { EDFA (dBm) }\end{array}$ & $\begin{array}{c}\text { Spectral optical } \\
\text { Backward } \\
\text { Signal power of } \\
\text { EYCDFA and } \\
\text { EDFA (dBm) }\end{array}$ \\
\hline $\begin{array}{l}\text { Dual } \\
\text { Forward } \\
\text { and } \\
\text { Backward } \\
\text { Pumping }\end{array}$ & 5 & 19.5 & 9.28 & 24.53 & -21.27 & 8.72 \\
\hline $\begin{array}{l}\text { Dual } \\
\text { backward } \\
\text { Pumping }\end{array}$ & 18 & 21.59 & 8.5 & 25.3 & -68 & 9.63 \\
\hline $\begin{array}{l}\text { Tri- single } \\
\text { forward } \\
\text { and dual } \\
\text { backward } \\
\text { pumping }\end{array}$ & 19 & 22.2 & 17.3 & 25.57 & -24.7 & 5.5 \\
\hline $\begin{array}{l}\text { Quad- } \\
\text { single } \\
\text { forward } \\
\text { and } \\
\text { backward- } \\
\text { pumping }\end{array}$ & 23.9 & 25.2 & $\mathbf{2 9}$ & $\mathbf{3 0 . 5}$ & -70.5 & $\mathbf{2 . 4 3}$ \\
\hline
\end{tabular}

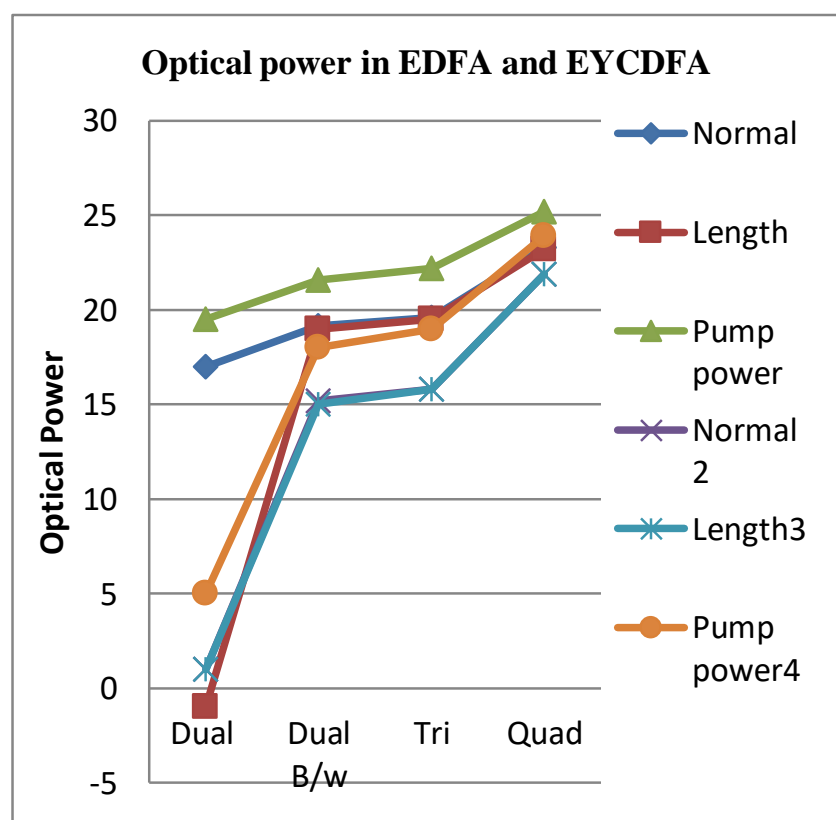

Fig 8. Optical Power output of EDFA and EYCDFA 
TABLE 3- Optical power meter output and OSA output of EDFA and EYCDFA with Pump power $=20 \mathrm{~dB}$ and Leng th $=10 \mathrm{~m}$

EDFA=10m, EYCDFA=1m, Multiplexed output= -2.9dB, Pump power $=20 \mathrm{~dB}$ and $I n p u t$ power $=1 \mathrm{mw}(0 \mathrm{~dB})$

\begin{tabular}{|c|c|c|c|c|c|c|}
\hline $\begin{array}{c}\text { Optical } \\
\text { amplifier } \\
\text { with type of } \\
\text { pumping } \\
\text { used }\end{array}$ & \multicolumn{2}{|c|}{$\begin{array}{c}\text { Optical } \\
\text { Power output } \\
\text { of EYCDFA } \\
\text { and EDFA } \\
\text { (dBm) }\end{array}$} & \multicolumn{2}{|c|}{$\begin{array}{c}\text { Spectral } \\
\text { optical } \\
\text { Forward } \\
\text { Signal power } \\
\text { of EYCDFA } \\
\text { and EDFA } \\
(\mathrm{dBm})\end{array}$} & \multicolumn{2}{|c|}{$\begin{array}{c}\text { Spectral optical } \\
\text { Backward Signal } \\
\text { power of EYCDFA } \\
\text { and EDFA }(\mathrm{dBm})\end{array}$} \\
\hline $\begin{array}{l}\text { Forward } \\
\text { and } \\
\text { Backward } \\
\text { Pumping }\end{array}$ & 1 & -1 & 5 & 10 & -24 & 10 \\
\hline $\begin{array}{l}\text { Dual } \\
\text { backward } \\
\text { Pumping }\end{array}$ & 15 & 19 & 2.88 & 22.9 & -72.7 & -17 \\
\hline $\begin{array}{l}\text { Tri- single } \\
\text { forward and } \\
\text { dual } \\
\text { backward } \\
\text { pumping }\end{array}$ & 15.8 & 19.5 & 14.6 & $\begin{array}{l}23.2 \\
5\end{array}$ & -25.47 & -22 \\
\hline $\begin{array}{l}\text { Quad- single } \\
\text { forward and } \\
\text { tri- } \\
\text { backward } \\
\text { pumping }\end{array}$ & 21.9 & 23.2 & 27 & 28.3 & -70.7 & -25.4 \\
\hline
\end{tabular}

Table 1, Table 2 and Table 3 shows the values measured from the simulation model output stage of each device, tabulated, and analyzed. Table 1 fixed the values are EDFA length $=5 \mathrm{~m}$, EYCDFA length $=1 \mathrm{~m}$, Multiplexed output= $2.9 \mathrm{~dB}$, Pump power $=20 \mathrm{~dB}$ and Input power $=1 \mathrm{mw}(0 \mathrm{~dB})$. Table 2 fixed the values are EDFA length $=5 \mathrm{~m}$, EYCDFA length $=1 \mathrm{~m}$, Multiplexed output $=-2.9 \mathrm{~dB}$, Pump power $=21.7 \mathrm{~dB}$ and Input power $=1 \mathrm{mw}(0 \mathrm{~dB})$. Table 3 fixed the values are $E D F A=10 \mathrm{~m}, \mathrm{EYCDFA}=1 \mathrm{~m}$, Multiplexed output $=-2.9 \mathrm{~dB}$, Pump power $=20 \mathrm{~dB}$ and Input power $=1 \mathrm{mw}$ $(0 \mathrm{~dB})$. The optimized result obtained in all three tables quad pumping gives better result.

\section{CONCLUSION}

We summarize the EDFA and EYCDFA power booster successfully simulated with various pumping like single forward and backward pumping, dual backward pumping, tri single forward and dual backward pumping and quad pumping techniques. From the all types of pumping Quad pumping is the best model for secured high power optical fiber communication and multiple wavelength services. Because it used multiple wavelength ranges from $1200 \mathrm{~nm}$ to $1600 \mathrm{~nm}$ and also it gives more security to data communication systems by giving large wavelength spacing $100 \mathrm{GHz}$ in Wavelength division multiplexing technique.
The EDFA-EYCDFA power booster model simulated with different pump powers and fiber lengths and obtained the output parameters are output optical power, Gain, Noise Figure, Forward signal and noise power and backward signal and noise power measured from the output of every device, tabulated the values, and analyzed. Quad- single forward and tri-backward pumping gives very high power and optimum forward signal and less backward signal power and can be the best model for optical data communication using fibers.

\section{REFERENCES}

[1]. Deepak Goyal, Hardeep Singh ,(2013)" Performance Evaluation of Optical Amplifier for $96 \times 10$ Gbps Optical Communication System", International Journal of Engineering Trends and Technology (IJETT) - Volume4 Issue6.

[2]. Sameksha Bhaskar1 , M.L.Sharma, Ramandeep Kaur," Performance Comparison of different hybrid amplifiers for different numbers of channels ",International Journal of Advanced Computer Science and Applications,Special Issue on Wireless \& Mobile Networks.

[3]. G. Sacchi, S. Sugliani, A. Bogoni, F. Di Pasquale, Member, IEEE, R. Di Muro, R. Magri, G. Bruno, and F. Cavaliere, (2005) " Design and Experimental Characterization of EDFA-Based WDM Ring Networks With Free ASE Light Recirculation and Link Control for Network Survivability", JOURNAL OF LIGHTWAVE TECHNOLOGY, VOL. 23, NO. 3.

[4] 1Inderpreet Kaur, Dr. Neena Gupta,(2010)" A Novel Approach For Performance Improvement ofDWDM Systems Using TDFA-EDFA Configuration”, IJECT Vol. 1, Issue 1.

[5]. B.Bala Subbanna, L.P.Divya Meenakshi, (2013) “ The Role of Optical Amplifiers in Optical Fiber Communication", International Journal of Engineering and Advanced Technology (IJEAT) ISSN: 2249 - 8958, Volume-2, Issue-4

[6]. Ravinder Kumar1, Poonam Singhal2, Tarun Gupta3," (2013) Comparison of Optical Amplifiers" , IJEEMF International Journal of Electrical, Electronics and Mechanical Fundamentals, Vol. 08, Issue 01.

[7]. Ronak R. Vashi1, Arpan H. Desai2 and Amit H. Choksi3, (2013) "Modeling of Gain Flattening using EDFAEYCDFA in Cascading Mode". International Journal of Emerging Trends \& Technology in Computer Science (IJETTCS) Volume 2, Issue 4.

[8].G. Ivanovas, V. Bobrovas, (2014) "Application of EDFA in WDM systems", International journal of physical sciences, Vol [5] PP 91-101.

[9].Sunil Kumar Panjeta, Onkar Chand, Danvir Mandal, (2012), "Gain optimization of EDF amplifier by stages 
International Journal of Engineering Applied Sciences and Technology, 2021

Vol. 5, Issue 12, ISSN No. 2455-2143, Pages 195-201

Published Online April 2021 in IJEAST (http://www.ijeast.com)

enhancement and variation in input pump power", International Journal of Scientific and Research Publications, Volume 2, Issue 11

[10]. Ravinder Kumar1, Poonam Singhal2, Tarun Gupta3, (2013), "Comparison of Optical Amplifiers",
IJEEMF International Journal of Electrical, Electronics and Mechanical Fundamentals, Vol. 08, Issue 01. 